\title{
Tomàs Baiget, editor científico, responsable del grupo Profesional de la Información
}

\author{
Entrevista realizada por LUIS RODRÍGUEZ YUNTA \\ CSIC, Centro de Ciencias Humanas y Sociales
}

\begin{abstract}
Entrevista que se centra en la labor de Tomàs Baiget como editor científico especializado en el área de Ciencias de la Documentación. Se destaca su actividad y trayectoria profesional, así como su visión sobre la disciplina, la labor de las revistas y la edición científica.
\end{abstract}

Profesional de la información, edición científica, historia de la Documentación, revistas académicas, revisión por pares, función del editor, prospectiva

Luis Rodríguez Yunta (LRY). Hola Tomàs. Antes que nada, agradezco a SEDIC la oportunidad de hacerte esta entrevista que centraremos sobre todo en tu labor actual como principal responsable del grupo editorial Profesional de la Información. Pienso que, como editor científico, has sido un importante agente en el desarrollo y consolidación de la Documentación como disciplina científica en España, para la que la revista Profesional de la Información es un claro referente. La propia denominación de la publicación surgió en un momento en el que había un debate abierto para buscar una denominación común a diferentes profesiones, para englobar a bibliotecarios y documentalistas junto a otros muchos puestos y funciones que podían surgir con las nuevas tecnologías. ¿Crees que se ha conseguido que un amplio conjunto de profesiones se identifique con esta etiqueta común?

Tomàs Baiget (TB). No, no se ha conseguido, ni creo que vaya a conseguirse. En la época del fuerte debate, allá por los $80 \mathrm{~s}$ y 90 s, cuando en el entorno de la flamante Sociedad de la Información se vivió cierta euforia con la creación de facultades de Biblioteconomía y Documentación, algunos propusieron buscar esa denominación común, pero el mundo bibliotecario tradicional se resistió a abandonar la palabra "Biblio-", que desgraciadamente circunscribe la profesión al espacio físico de las bibliotecas y a los libros. Es como si los médicos se denominaran "hospitaleros", los abogados "tribunaleros" y los arquitectos "caseros". Como consecuencia los "bibliotecarios" salidos de las facultades no eran aceptados para trabajar en empresas en las que no hay biblioteca, que son la inmensa mayoría. En ese momento de cambio y renovación hubiera sido ideal adoptar la denominación que propugnó Alfons Cornella: Infonomía, pero se consideró algo descabellado. Recientemente la Facultad de ByD de la UB dio un paso positivo adoptando el nombre Facultad de Información, pero creo que no hacía falta que añadieran "y Medios Audiovisuales" solo porque esta especialidad de la Información coyunturalmente puede atraer más alumnado.

Bajo el principio de que el acceso abierto a los resultados de investigación acelera el avance del conocimiento, todos los contenidos de la edición electrónica de CLIP se distribuyen bajo una licencia de uso y distribución Creative Commons Reconocimiento-NoComercialCompartirlgual 3.0 España (CC BY-NC-SA 3.0 ES). 

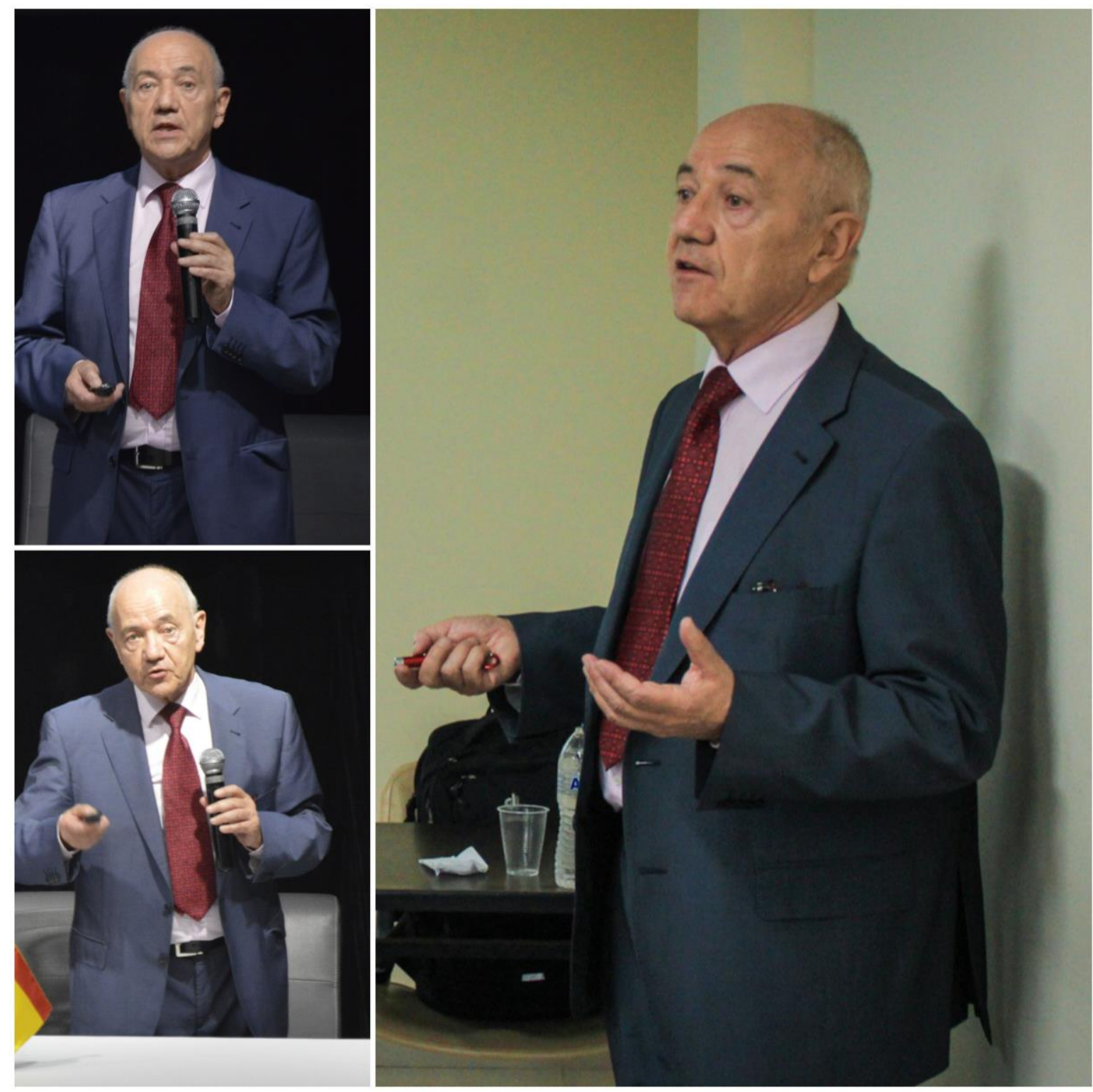

Tomàs Baiget

LRY. Mirando a tus primeros pasos, como ingeniero industrial eléctrico, te viste envuelto en los inicios de la entonces llamada "Teledocumentación" allá en los años 70. Pienso que en aquellos tiempos se vivía una clara separación entre un campo profesional incipiente y muy técnico de documentalistas ligados al desarrollo de bases de datos, frente a un mundo de las bibliotecas aparentemente más tradicional. Estos sectores fueron confluyendo y a ello han contribuido las asociaciones profesionales, los congresos de Documat que luego asumió Fesabid y finalmente la lista IweTel en la que sigues participando en la gestión. A lo largo de estos años, ¿cómo has vivido tú esta evolución?

TB. En 1973 tuve la suerte de ser uno de los pioneros en Europa del acceso online a bases de datos gracias a unas actividades filantrópicas mías (siempre digo que el altruismo da réditos), y eso cambió mi futuro, pues yo que había trabajado en Philips en Barcelona estaba estudiando 
Telecos en Madrid y pensaba seguir dedicándome a la electrónica. Ser experto en teledocumentación en esa época era estar en la cresta de la ola. Estuve haciendo demostraciones en varias ciudades a petición de Telefónica. Como curiosidad, en el SIMO de 1974 hice una búsqueda sobre veleros para los príncipes Juan Carlos y Sofía: ¡solo apareció una referencia! Las bases de datos maravillaban, pero aún eran muy reducidas.

En 1977 la Fundación de la Telefónica (Fundesco) me contrató para organizar un curso de 100 horas para formar a 20 licenciados: fueron los "consultores-analistas" especializados por temas, que llevaban a cabo búsquedas bibliográficas preparadas mediante un exhaustivo formulario de 6 páginas (!). El acceso a las bases de datos era muy caro y antes de conectar se tenía que haber preparado el tema, su terminología, estrategias de búsqueda alternativas... Fui el jefe técnico de la Red de Información Cientifica Automatizada (Red INCA), un proyecto de Fundesco que luego se convirtió en la fundación Fuinca, ya desaparecida. Red INCA dio ayudas económicas y asesoramiento para instalar terminales de teledocumentación en algunas universidades españolas.

Internet lo cambió todo. Con telecomunicaciones rápidas y baratas, fácil acceso a los textos completos, y abundantísima información en gran parte gratuita, las bases de datos solo bibliográficas clásicas perdieron casi todo su protagonismo.

En los años 70 y 80 se crearon cientos de bases de datos y decenas de distribuidores online (hosts o servidores) pero la mayoría de los europeos ofrecían poca información y su uso era complicado (tenían lenguajes de consulta distintos), por lo que no eran atractivos. Los estados europeos no supieron colaborar y crear un host común. Hubo muchos proyectos con inversiones millonarias que fracasaron. En cambio, el host norteamericano Dialog que distribuía 400 bases de datos consultables con un lenguaje común para todas, sí fue un negocio rentable. En su momento fue la gran estrella de los Online Information Meetings de Londres, pero con la llegada de la digitalización masiva e internet fue perdiendo valor e interés, pasó por varias manos y hoy día, instalado en ProQuest, lo usa tan solo una minoría.

De paso, también podemos recordar aquí toda la malograda aventura del videotex que ocasionó la frustración y la ruina de los pioneros que apostaron por el sistema en los 80 y 90.

LRY. Tras varias revoluciones tecnológicas y la explosión de una sociedad actual hiperconectada, la labor de los documentalistas técnicos parece haber quedado diluida porque ya no se demandan intermediarios en la consulta de información. Por el contrario, las bibliotecas sí se mantienen como instituciones renovadas que facilitan el acceso a las fuentes de información. ¿Crees que la documentación científica tiene aún futuro o que el sector de los profesionales de la información se va a quedar limitado al empleo que puedan ofrecer las bibliotecas? ¿Cómo se percibe esto desde el campo de la edición?

No te puedo contestar desde la edición, porque casi nadie publica ya sobre bases de datos. Parece un tema desaparecido. Creo que el profesional documentalista científico, como intermediario, seguirá siendo necesario (no me atrevo a decir imprescindible) solo en algunas especialidades, como la medicina, biología, química, o patentes. Como editor sí puedo decir que algunos autores hacen investigaciones bibliográficas con ecuaciones de búsqueda defectuosas (incompletas, redundantes, con silencios y con ruidos...). Cuando en la Redacción leemos los artículos con los resultados nos quedamos con la duda de hasta qué punto estuvo mal hecha y si merecería la pena echar para atrás el artículo, aunque haya superado la revisión por pares. Esos autores deberían haber realizado la búsqueda con la ayuda de expertos del CRAI de su universidad.

LRY. En las revistas se reciben buenos artículos, pero también otros no tan buenos. A menudo, los autores presentan textos que no tienen suficiente preparación, no están bien enfocados o sencillamente están mal escritos. Si el tema tratado tiene suficiente interés, toca a los equipos editoriales hacer una función pedagógica. Como experto que has dado cursos a los autores sobre 
como escribir buenos artículos, ¿qué recomendaciones principales puedes hacer para autores con menor experiencia?

Lo primero, ser ambiciosos en la investigación. Las revistas recibimos demasiados artículos que no aportan casi nada nuevo, analizan temas efímeros o intrascendentes, con muestras de población pequeñas o muy locales, con métodos elementales, con hipótesis que ya se prevé de entrada que se confirmarán. Esos artículos solo sirven para llenar las páginas de revistas de poco nivel que no tienen otra cosa para publicar, y son una pérdida de tiempo.

Lo segundo es ser consciente de que escribir bien es muy difícil, y con frecuencia se requiere tener la humildad de pedir la ayuda de colegas expertos que ayuden, aceptando sus sugerencias de mejora de la redacción.

LRY. ¿Crees que la función del editor es hoy suficientemente valorada? ¿Es necesario que existan las revistas científicas para dar las mejores garantías posibles de rigor en la publicación de artículos de investigación?

Pues no, no se valora el trabajo de los editores. Hay una extendida creencia de que no hacemos nada, incluso algunos llegan a decir que entorpecemos la difusión de la ciencia. El de editor es un trabajo muy vocacional, realizado en la oscuridad. Los que lo hacemos ya lo tenemos asumido, y estamos convencidos que hacemos un buen servicio a los demás. Sin contar las horas que dedican los evaluadores a juzgar los manuscritos, luego, por ejemplo, en la Redacción de EPI, entre 3 personas trabajando en cadena, dedicamos un mínimo de 8 horas a cada artículo revisando los textos a fondo, mejorando la gramática y legibilidad (y con frecuencia descubriendo errores), mejorando las tablas y los gráficos, añadiendo ilustraciones, comprobando que funcionen los dois y urls...

A diferencia de los repositorios, donde solo se realizan controles formales y permiten almacenar cualquier documento, las revistas tenemos una "marca" cuya reputación intentamos mantener y aumentar, creamos una canal de difusión que da confianza a lectores y autores, ofrecemos una garantía de veracidad y de calidad mantenida a lo largo de años (29 en el caso de $E P I)$.

LRY. Personalmente siempre agradeceré al Profesional de la Información que, como autor, fue en esta publicación donde por primera vez recibí evaluaciones serias a un trabajo mío, que pude mejorar a partir de apreciaciones realmente útiles y bien trabajadas por los revisores. Luego he tenido la oportunidad de colaborar en otros roles, como revisor y más tarde como parte del equipo editorial, pero pienso que sin esa primera experiencia de autor que saca fruto de ser evaluado no es posible abordar con rigor las demás funciones. Pero sabemos que el sistema de evaluación por pares tiene también sus debilidades, ¿cuál es tu opinión actual sobre su funcionamiento?

La evaluación por pares es un proceso imprescindible para asegurar que la investigación que se publica es rigurosa, y es el máximo valor que aportamos las revistas. Primero en la Redacción hacemos un filtraje inicial -ahí se rechaza el 65\%-, y luego gestionamos la evaluación a cargo de colegas externos. Cuando el artículo ya está aprobado, nuestro análisis a fondo de los textos aporta otras revisiones más.

La evaluación por pares requiere la dedicación altruista de estos, y es una de las cosas bonitas que tiene este sistema: que muchas personas dedican una buena parte de su precioso tiempo a revisar artículos de otros que ni siquiera conocen. Los pares evaluadores son profesores de universidad que ya tienen un cierto nivel científico y que normalmente van a tope de actividad. Tienen que dejar aparte sus propias tareas e investigaciones para regalar unas horas a la revista. 
Digo regalar porque la gran mayoría de revistas no disponemos de dinero para compensar mínimamente esta importantísima labor.

Pero también tiene problemas. En la práctica, la gestión de las revisiones es complicada y lleva mucho tiempo a los coordinadores editoriales de la revista, pues es difícil encontrar los evaluadores adecuados para cada tema que estén disponibles para llevar a cabo una evaluación a fondo y en poco tiempo. Con frecuencia las respuestas se retrasan, o se tienen que cancelar la peticiones y buscar sustitutos. En EPI tenemos una lista con más de 500 investigadores, pero muchas veces resulta corta.

Por otro lado, la evaluación por pares es un proceso frágil, que puede fallar en su objetivo de certificar la validez de una investigación. Se producen casos de falsificación, que es difícil de detectar cuando se trata de investigaciones complicadas realizadas con equipos o programas sofisticados, con muchas personas..., aunque en ciencias sociales parece que todo es más controlable que en ciencias experimentales. Otras veces los resultados contienen errores de cálculo involuntarios que el evaluador puede no haber comprobado y se corre el riesgo de que pasen a ser publicados.

LRY. Aparte del acierto en seleccionar evaluadores, pienso que la clave del éxito del Profesional de la Información es haber mantenido una frecuencia bimestral, lo que solo es posible con un equipo de trabajo estable y con una alta dedicación, tanto en la gestión como en la difusión posterior. Como editor siempre te has distinguido por defender que la elaboración de una revista debía profesionalizarse. ¿Cuál es el número de personas que actualmente trabaja en la revista y que grado de profesionalidad se ha alcanzado?

Efectivamente, si se quiere prosperar como revista científica hay que ir aprendiendo el oficio a lo largo de años y luego, como he dicho, dedicar mucho tiempo. Ahora estamos 2 personas a tiempo completo, y 6 a tiempo parcial. Dos colaboradores más ofrecen soporte ocasional. No tenemos ninguna sede física, desde hace años trabajamos online y estamos repartidos entre Barcelona, Bogotá, Bucarest, Castellón, León, Madrid, Tenerife y Caracas.

En cuanto a "profesionalidad" creemos que tenemos bastante, más que nada por el hecho de vernos reconocidos al estar indexados en varias bases de datos como WoS, Scopus, Inspec..., tener el Sello de Calidad Fecyt, etc. Pero nos falta. Nunca se puede abarcar todo, faltarían más personas dedicadas a la revista a tiempo completo, hacemos cosas con las que aún nos sentimos inseguros, algo novatos, por falta de tiempo para dedicarnos a ellas más a fondo. Tenemos que estudiar sobre nuevas formas de presentación de la revista, sistemas anti-plagio, promover la disponibilidad de los datos de investigación, preservación, más internacionalización...

LRY. La revista EPI es hoy un referente en el campo no solo de las Ciencias de la Documentación, sino también en el de Comunicación. La ampliación de la temática, ¿'ha sido motivada por la necesidad de búsqueda de ingresos para la pervivencia económica de la publicación o porque se percibe una creciente confluencia entre estos dos sectores?

Hemos entrado en la Comunicación principalmente por la falta de producción de artículos de Documentación, una disciplina que parece haber quedado estancada, a excepción de la bibliometría (que realmente siempre ha sido un apéndice separado). Además, lo poco que se publica se limita generalmente a los estudios de caso. En cambio, en Comunicación se ha producido una verdadera explosión de investigaciones. Tengo la impresión de que las dos disciplinas han confluido muy poco, a pesar de que haya facultades que las tienen integradas. 


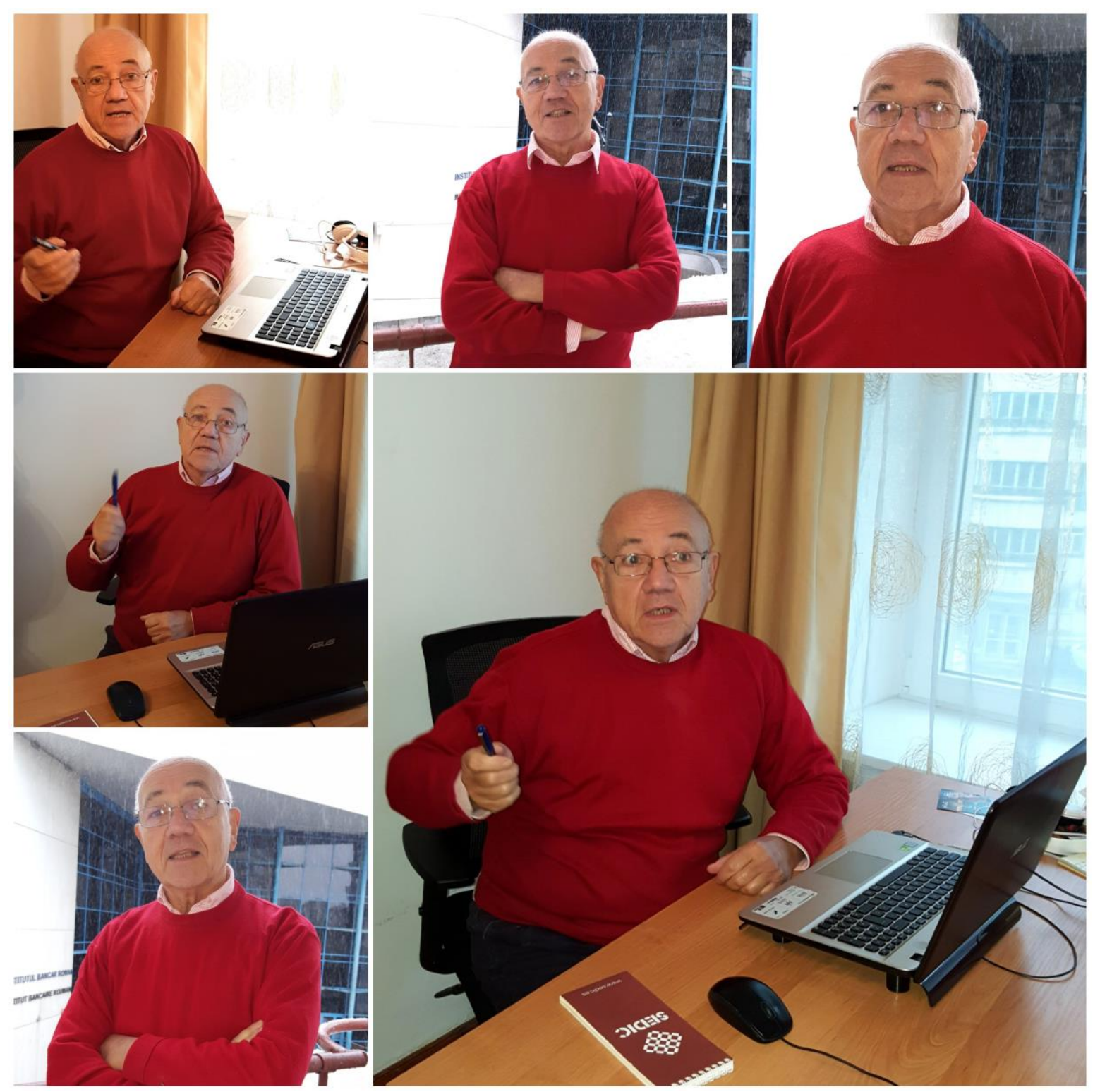

LRY. Aunque la revista acepta artículos de tema libre se hacen convocatorias, los clásicos callfor-papers, sobre temas específicos. La elección de estos temas puede tomarse como una muestra de los aspectos que os han parecido más relevantes, y por tanto como un pulso de la evolución de estas disciplinas. ¿Cuáles has sido los de mayor éxito de convocatoria y qué temas se barajan para los próximos?

Algunos temas han sido propuestos por investigadores senior, que luego actúan como coordinadores o editores invitados. Otros los hemos decidido en la Redacción a raíz de asistir a congresos, lo que ayuda a percibir que temas pueden ser más atractivos en este momento. Los monográficos más exitosos han sido "Comunicación política", "Información científica", "Públicos vulnerables y empoderamiento digital", "Edición y difusión del libro" y "Nuevos medios". 
Y el que menos, con diferencia, uno político-económico: "Estructuras de poder en comunicación". Era previsible, pues hay pocos investigadores que trabajen en esta área, que consideramos importantísima. Intentamos forzar a ver si algunos se animaban a investigar, pero no tuvimos éxito.

Tenemos temas programados y comprometidos con editores invitados hasta julio de 2022. Los próximos son "Imágenes y verdad" (marzo de 2021), "Periodismo hi-tech" (mayo de 2021), "Interacción y visualización" (julio de 2021), "Información y comunicación de la sexualidad" (sept. de 2021)... Estamos ilusionados con este último por tratar un tema poco frecuente en nuestro campo, sobre el cual todavía hay algunos que se ruborizan. Contaremos con un editor especialista de la University of Nevada.

LRY. Dentro del mismo grupo, el Anuario ThinkEPI representa un modelo muy diferente de publicación científica, basado en un think tank de expertos en Documentación. ¿Qué motivó la apuesta por crear una segunda cabecera? ¿Ha sido una experiencia exitosa?

Sí, estamos satisfechos. Es una publicación que ha ido subiendo de nivel y de impacto casi sin proponérnoslo. En el ranking de revistas de Documentación de Dialnet es la $5^{\text {a }}$ revista sobre 23, y en el ranking según el índice h de Google Scholar Metrics (2014-2018) de la UGR es la $4^{a}$ sobre 14.

Lo puse en marcha en 2007 simplemente para recoger los posts que los componentes del Grupo ThinkEPI enviaban por la lista IweTel. Se trata de notas cortas sobre temas de la profesión, pequeños ensayos para reflexionar, que han resultado muy interesantes y son muy citados. Sus autores son profesores e investigadores que ya tienen una larga trayectoria en Documentación y Comunicación. Aparte de IweTel no existía un canal de difusión formal para este tipo de escritos que no son las sesudas investigaciones que se publican en los artículos normales de las revistas. El Anuario se publicó en papel hasta 2013, y desde entonces ya solo online. Actualmente es una publicación de acceso abierto con edición progresiva a lo largo del año.

LRY. A partir de la salida anual del Anuario ThinkEPI comenzaron a organizarse las conferencias $C R E C S$ sobre calidad de las revistas científicas, que iban a celebrar en 2020 su XI $^{\mathrm{a}}$ edición en León, pospuesta por la pandemia. En estas sesiones, que se convirtieron en internacionales, participan gestores de revistas junto a profesionales de servicios bibliotecarios y plataformas editoriales. ¿Qué conclusiones extraes de las últimas ediciones? ¿Qué cambios serían necesarios en el sector de las revistas científicas?

Las CRECS han resultado un éxito gracias al mix de participación, que ha permitido aprender unos de otros, cada uno a su nivel y tipo de tarea. Es un placer ver a los asistentes satisfechos al terminar la conferencia, animados y dispuestos a aplicar en su trabajo lo aprendido. Creo que tú mismo, Luis, que has presentado las conclusiones de cada edición, podrías expresarlas aquí mejor que nadie. Además, tú has analizado la situación de las revistas a través de interesantísimos artículos.

En mi opinión la situación de las revistas no es mala ni precisa cambios grandes o urgentes, aunque hay varias cosas deseables. La más importante: recibir ayudas para profesionalizarse, poder pagar las evaluaciones y acelerar el proceso de los artículos. Como dije antes, la evaluación por pares es el cuello de botella y lo más frágil de cualquier revista.

LRY. Como colaborador en las ediciones de CRECS, puedo decir que siempre me ha sorprendido que cada año se logra presentar alguna novedad, que se puede interpretar como reto para los editores. $\mathrm{Y}$, sin embargo, también permanecen problemas muy difíciles de abordar, como la excesiva atomización o dispersión de títulos con poca producción, o la falta de reconocimiento para los editores. En parte, la edición de revistas abre camino en la búsqueda 
de mejorar profesionalidad y difusión, que poco a poco van abordando otros campos como las monografías científicas. El Profesional de la Información también ha abordado la edición de libros. ¿Es una labor ya finalizada o sigue teniendo títulos en proyecto?

Seguimos en ello. Tenemos dos colecciones editadas mediante un convenio con la Editorial UOC: EPI-UOC de libros de bolsillo, ya con 50 títulos, y EPI-Scholar con 12 títulos. Reciente hemos publicado un Manual de gestión de revistas científicas.

LRY. Además de la edición científica, has mantenido la colaboración con otras muchas iniciativas de pueden ser de interés para los lectores de Clip. ¿Cuáles destacarías?

Siempre he intentado ser un "constructor de enlaces profesionales" para dar más solidez a nuestra comunidad, y a su vez varios de los proyectos están interconectados. Para llevarlos a cabo he tenido ayudas imprescindibles de muchos colegas, sin ellos no hubiera podido. He puesto mi granito de arena en la creación de asociaciones (Asedie, Socadi), una web para mentalizar sobre la importancia de la firma de los trabajos científicos (IraLIS), un directorio con fotos para ayudar a que todos nos conozcamos más (Directorio EXIT), apoyo a un repositorio para promocionar y conservar nuestros trabajos (e-LIS), una cronología de la documentación española (Crodoc), las listas de correo IweTel, Incyt y Comunicación... También hubo proyectos que fallaron después de haber invertido muchos esfuerzos, como Ciepi, Documenea y Docupedia...

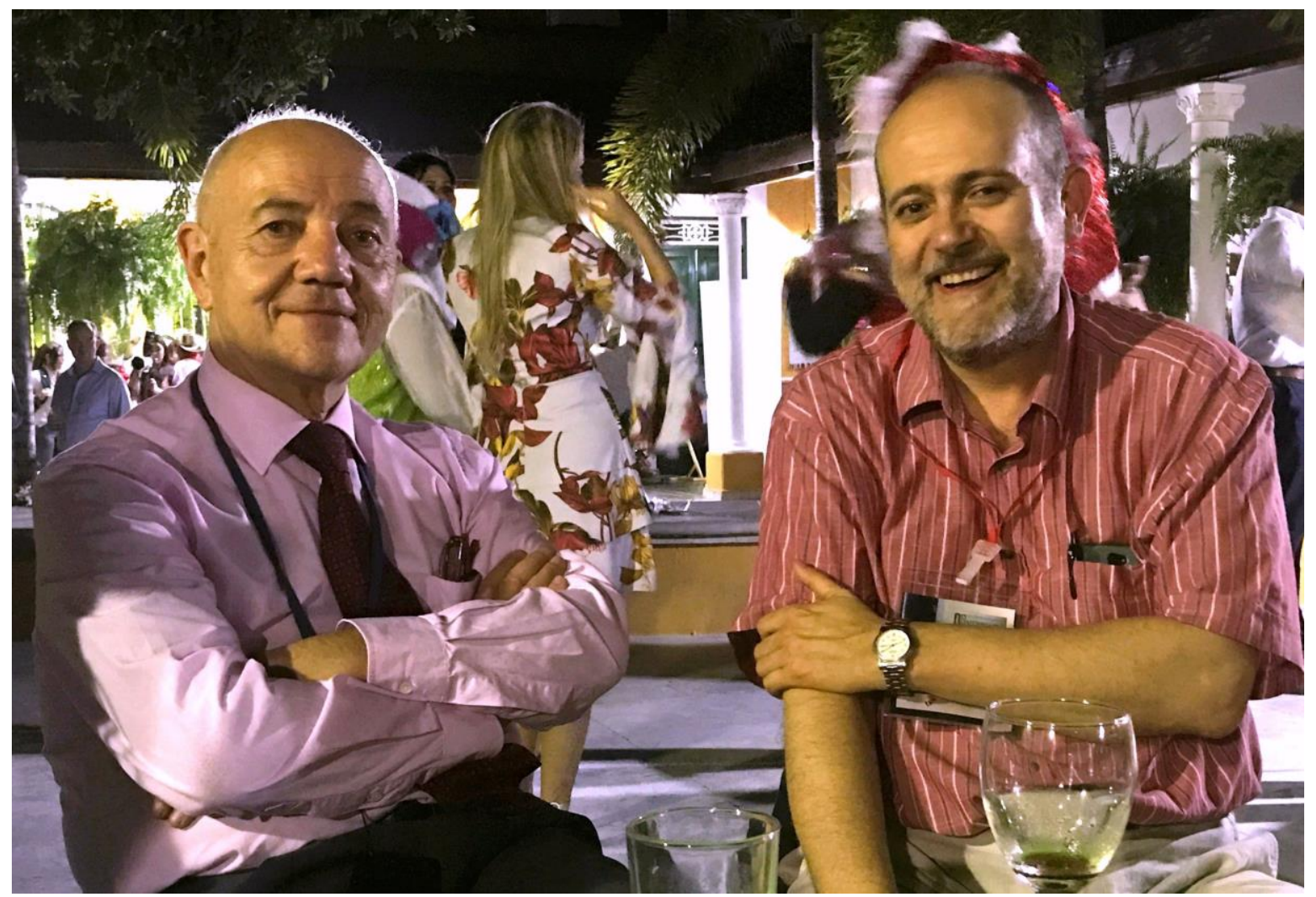

Tomàs Baiget con Luis Rodríguez Yunta, autor de la entrevista 


\section{Autor de la entrevista:}

\section{LUIS RODRÍGUEZ YUNTA}

Diplomado en Formación del Profesorado de EGB, licenciado en Historia y doctor en Documentación por la Universidad Complutense de Madrid (UCM). Ha trabajado en los servicios de documentación del Consejo Superior de Investigaciones Científicas (CSIC) desde 1986 -en el ISOC, el Cindoc y actualmente el Centro de Ciencias Humanas y Sociales-. A partir de 2015 es responsable de la Unidad de Apoyo a la Edición de Revistas en dicho centro. Ha sido profesor asociado en la Facultad de Documentación de la UCM en los periodos 2007-2010 y 2013-2016. Ha formado parte de la Junta Directiva de la asociación profesional Sedic y de la red de centros europeos Redial. Entre 2014 y 2019 ha trabajado en el equipo de redacción de la revista Profesional de la información y desde 2017 es director de Anuario ThinkEPI.

- $\quad$ https://orcid.org/0000-0002-8424-6205

- 1 uis.ryunta@cchs.csic.es 